\title{
The Frequency Detection of Opportunistic Sexually Transmitted Infections among HIV-Infected Women Planning Pregnancy
}

\author{
Elena Belyaeva, PhD*; Eleva Genich, PGS; Olga Leshchenko MD, PhD \\ Scientific Centre for Family Health and Human Reproduction Problems \\ Irkutsk, the Russian Federation
}

\begin{abstract}
The purpose of our study was to determine the frequency of detection of opportunistic sexually transmitted infections (Chlamydia trachomatis, Trichomonas vaginalis, Ureaplasma spp, Human papillomavirus) in HIV-infected women planning pregnancy.

Methods and Results: We examined 31 HIV-positive Caucasian women. They sought pregnancy planning advice at the Scientific Center for Family Health and Human Reproduction Problems in Irkutsk during 2014-2015. The average age of the women was 30.9 \pm 4.5 years (20-39 years). A clinical diagnosis of HIV was made at Irkutsk Regional AIDS Center. All HIVinfected women were tested for the presence of DNA of pathogens of bacterial and viral sexually transmitted infections in the epithelium of the cervical canal. Chlamydia trachomatis was detected in 1(3.2\%) participant, Trichomonas vaginalis in 1(3.2\%), Ureaplasma spp. in 14(45.2\%), and HPV in 22(71\%). Co-infection of HPV and Ureaplasma spp. was observed in 35.5\% of HIVpositive women.

Conclusion: the prevention and detection of sexually transmitted infections in HIV-infected individuals remain a public health priority and an integral component of HIV primary care.(International Journal of Biomedicine. 2021;11(4):505-510.)
\end{abstract}

Key Words: HIV • HPV • Chlamydia trachomatis • Trichomonas vaginalis $・$ Ureaplasma spp.

For citation:Belyaeva E, Genich E, Leshchenko O. The Frequency Detection of Opportunistic Sexually Transmitted Infections among HIV-Infected Women Planning Pregnancy. International Journal of Biomedicine. 2021;11(4):505-510. doi:10.21103/Article11(4)_OA16

\section{Abbreviations}

AIDS, acquired immunodeficiency syndrome; ASCUS, atypical squamous cells of undetermined significance; cART, combination antiretroviral therapy; HAART, highly active antiretroviral therapy; HIV, human immunodeficiency virus; HPV, human papillomavirus; HSIL, high-grade squamous intraepithelial lesion; LSIL, low-grade squamous intraepithelial lesion; OpIs, opportunistic infections; PCR, polymerase chain reaction; PID, pelvic inflammatory disease; STDs, sexually transmitted diseases; STIs, sexually transmitted infections.

\section{Introduction}

Human immunodeficiency virus (HIV) is a critical public health problem. ${ }^{(1,2)}$ By July 2020 at the global level, there were 38 million people infected with HIV; of these, more than 19 million were women. ${ }^{(3)}$ Russia has the highest

*Corresponding author: Elena Belyaeva, PhD. Scientific Centre for Family Health and Human Reproduction Problems, Irkutsk, the Russian Federation.E-mail: belyeva irk@mail.ru
HIV incidence rate in Europe with more than 1.2 million HIV-infected people. ${ }^{(4)}$ Among the regions of the Russian Federation, the Irkutsk Region (Eastern Siberia) has an unfavorable epidemiological situation for HIV; there were 29,200 people living with HIV by July 2021.(5) About 1204 new cases of HIV infection were detected in the 6 months of 2021. Of these, $98.3 \%$ were persons of reproductive age; the share of women among them was $44.3 \%{ }^{(5)}$

The use of combination antiretroviral therapy (cART) in HIV-infected patients led to an increase in their life expectancy, and as a result, an increased risk of 
developing concomitant diseases. ${ }^{(6)} \mathrm{HIV}$ infection progresses slowly, and its distinctive feature is the suppression of the immune system functions, which contributes to the risk of opportunistic infections (OpIs). Among them, a special place is occupied by STIs caused by bacteria and viruses since they have the most aggravating effect on reproductive health. ${ }^{(7,8)}$ In addition, patients with HIV co-infection have more severe oxidative stress than HIV-monoinfected patients, which can also contribute to the development of reproductive system disorders. ${ }^{(2,9,10)}$

Sexually transmitted diseases (STDs) lead to the formation of undesirable pathological conditions in young women of reproductive age. $\left({ }^{11,12)}\right.$ Most women know about STDs and AIDS and how to prevent them; however, just $40 \%$ use condoms. ${ }^{(13)}$ Curable STIs, including Chlamydia trachomatis, Neisseria gonorrhoeae, and Trichomonas vaginalis, are associated with adverse pregnancy outcomes. (14) Therefore, it is important to conduct screening for specific STDs during pregnancy and among women planning pregnancy. ${ }^{(15,16)}$

The purpose of our study was to determine the frequency of detection of opportunistic STIs (Chlamydia trachomatis, Trichomonas vaginalis, Ureaplasma spp, Human papillomavirus) in HIV-infected women planning pregnancy.

\section{Materials and Methods}

We examined 31 HIV-positive Caucasian women. They sought pregnancy planning advice at the Scientific Center for Family Health and Human Reproduction Problems in Irkutsk during 2014-2015. The average age of the women was $30.9 \pm 4.5$ years (20-39 years). We found that $22(71 \%)$ and $9(29 \%)$ women had secondary special education and secondary education, respectively; $7(22 \%)$ women were married, 13(42\%) had an unregistered marriage, 2(6\%) were single, $9(30 \%)$ were divorced; $22(71 \%)$ women had regular sex and $9(29 \%)$ women had irregular sex (less than 4 times per month); 19(61\%) women used condoms, 9(29\%) had interrupted sexual intercourse, 3(10\%) did not use any contraception, and 20(64\%) women had a permanent sexual partner - male with HIV infection.

A clinical diagnosis of HIV was made at Irkutsk Regional AIDS Center. HIV stage 4-A was found in 13(42\%) women, HIV stage 4-B - in 18(58\%) women. The average duration of HIV infection was $8 \pm 2.5$ years; $15(48 \%)$ patients received HAART. HIV was mainly transmitted sexually in $80 \%$ and through the parenteral route of transmission in $20 \%$ of cases.

All HIV-infected women were tested for the presence of DNA of pathogens of bacterial and viral STDs in the epithelium of the cervical canal: Chlamydia trachomatis, Trichomonas vaginalis, Ureaplasma species, HPV. We used the PCR method to detect the DNA of bacteria and viruses. We used reagents manufactured by the Central Research Institute of Epidemiology ("AmpliSens Chlamydia trachomatisFL," "AmpliSens Trichomonas vaginalis-FL," "AmpliSens Ureaplasma spp.-FL," "AmpliSens HPV HCR screen-Eph," AmpliSens HPV HCR genotype-EPh") and followed the manufacturer's instructions. Biological material was sampled with cervix brushes that were placed in vials with a transport medium (isotonic aqueous saline buffer solution with preservative). DNA was isolated from the obtained samples by sets of "DNA-Sorb-AM" reagents.

The PCR was done on a thermocycler "Tertsik" (Russia). The 4-channel rotor fluorimeter "ALA-1/4" (BioSan, Latvia) was used to detect end-point fluorescence after PCR runs with work reagents ("AmpliSens Chlamydia trachomatisFL," "AmpliSens Trichomonas vaginalis-FL," "AmpliSens Ureaplasma spp.-FL"). A 3\% agarose gel electrophoresis with ethidium bromide was used to detect DNA fragments after PCR runs with reagents ("AmpliSens HPV HCR screen-Eph," “AmpliSens HPV HCR genotype-Eph”).

Statistical analysis was performed using the statistical software STATISTICA (v10.0, StatSoft, USA). Group comparisons with respect to categorical variables are performed using chi-square tests or, alternatively, Fisher's exact test when expected cell counts were less than 5; z-test was used to analyze the differences in proportions. A value of $P<0.05$ was considered significant.

The study was carried out in compliance with Ethical Principles for Medical Research Involving Human Subjects, Adopted by the 18th WMA General Assembly, Helsinki, Finland, June 1964, and amended by the 64th WMA General Assembly, Fortaleza, Brazil, October 2013. The study was approved by the Ethics Committee of the Scientific Center for Family Health and Human Reproduction Problems. Written informed consent was obtained from each patient.

\section{Results and Discussion}

In our study, Chlamydia trachomatis was detected in $1(3.2 \%)$ participant, Trichomonas vaginalis in $1(3.2 \%)$, Ureaplasma spp. in 14(45.2\%), and HPV in 22(71\%). Only 6(19.4\%) HIV-infected women did not have opportunistic STIs. HPV and Ureaplasma spp. were observed most often, so we assessed infection with Ureaplasma spp. in two groups of patients with HIV infection. In Group 1 (22 women with HPV), Ureaplasma spp. was detected in $50 \%$ of cases, and in Group 2 ( 9 women without HPV) only in $33.3 \%$ of cases, but the differences were not statistically significant.

Earlier, we published that in a group of HIV-infected women, HPV type 16 was found in 16(51.6\%) and ranked the first among 12 types of HPV. ${ }^{(17)}$ Only 2(12.5\%) patients had HPV 16 mono-infection, and 14(87.5\%) had HPV type 16 combined with other types of HPV. Most HPV-positive women were infected with several (on average three) types of HPV. Also, we compared abnormal colposcopy results in two groups of HIV patients. ASCUS was detected in all patients of Group $1(100 \%)$ and in 6(66.7\%) patients of Group 2. In Group 1, 2(9.1\%) women were diagnosed with LSIL, $10(45.5 \%)$ with HSIL.

Currently, OpIs are a serious medical and social problem due to their widespread and adverse impact on the level of general and reproductive health of the population. ${ }^{(12)}$ In people without abnormalities of the immune system, such infections usually do not lead to the disease, but against the background 
of a reduced immune status, OpIs manifest, especially, in HIVinfected people. ${ }^{(18,19)}$ OpIs are peculiar markers of immunological problems and develop as a result of the progressive course of HIV infection. ${ }^{(17,19,20)}$

A study conducted in Ethiopia showed that the overall prevalence of OpIs among the HIV-infected people was 33.6\%, the majority being females - 206(53.6\%). ${ }^{(21)}$ Opportunistic diseases can be caused by various bacteria, viruses, and fungi, but among all their diversity, the leading role, according to the degree of influence on reproductive health, is assigned to STIs. In 2015, about 1.1 billion people had STIs other than HIV/AIDS. ${ }^{(22)}$ About 500 million people have been infected with Treponema pallidum, $N$. gonorrhoeae, Chlamydia trachomatis or Trichomonas vaginalis; at least an additional 530 million people have genital herpes, and 290 million women have HPV. ${ }^{(22)}$ STIs other than HIV resulted in 108,000 deaths in 2015. ${ }^{(23)}$

Some STIs in women often cause the serious condition of PID, (24) which can lead to infertility, chronic pain or death. ${ }^{(25,26)}$ In addition to the fact that PID itself is a serious disease, STIs can also increase the risk of both acquiring and transmitting HIV by 10 times. A systematic review of the prevalence of STIs among persons living with HIV demonstrated a mean point prevalence of STI co-infection of $16.3 \%(\mathrm{SD}=16.4$, median $=12.4 \%){ }^{(27)}$ In a study conducted in Tanzania among pregnant women, it was shown that the prevalence of STIs was greater in HIV-positive than in HIVnegative women. ${ }^{(28)}$

There are more than 20 types of pathogens that can be transmitted sexually.

Chlamydia is one of the most common STIs, caused by the bacterium Chlamydia trachomatis. In women, symptoms may include abnormal vaginal discharge, burning during urination, and bleeding in between periods, although most women do not experience any symptoms. ${ }^{(29)}$ Chlamydia can cause PID. In turn, PID can cause serious problems during pregnancy and even has the potential to cause infertility. In a study by Waung et al., the prevalence of chlamydia in HIVinfected patients was $5 \%,{ }^{(30)}$ which was comparable with our data $-3.2 \%$. Chlamydia screening should be performed on all women and men upon entry into care for HIV and then annually if sexually active. ${ }^{(31)}$

Trichomoniasis is a protozoal infection caused by Trichomonas vaginalis that infects the genital tract of both men and women. Women may present with vaginal discharge and men may present with urethritis, but both may also be asymptomatic. Trichomonas vaginalis affects $3.1 \%$ of women of reproductive age. ${ }^{(31)}$ However, among HIV-infected people, trichomoniasis is observed more often. Recent surveillance data obtained in a study by Meites et al. showed that the prevalence of Trichomonas vaginalis in HIV-infected women was $29.3 \% .{ }^{(32)}$ In a study by Kalichman et al., ${ }^{(27)}$ the prevalence of Trichomoniasis in HIV-infected patients was $18.8 \%$. A study conducted in pregnant women showed that trichomoniasis was present in $18.6 \%$ of HIV-positive and $10.2 \%$ of HIVnegative women. ${ }^{(33)}$ In our study, trichomoniasis was detected in $3.2 \%$ of HIV-infected women, which was less than in other studies. It should be noted that trichomoniasis is associated with adverse birth outcomes, such as premature delivery or rupture of the membranes and low birth weight; therefore, it is important to conduct a study for trichomoniasis for all women planning pregnancy. ${ }^{(33)}$

Ureaplasma infection is an infectious disease caused by a membrane parasite that occupies an intermediate position between unicellular microorganisms and viruses. Ureaplasma spp. has 14 known serotypes and is divided into two biovars - Ureaplasma parvum and Ureaplasma urealyticum. ${ }^{(34)}$ Ureaplasma spp belongs to opportunistic microflora, that is, a small amount of Ureaplasma spp. can inhabit the urogenital tract of healthy people without causing any pathological processes. However, in cases of favorable conditions for itself, Ureaplasma multiplies and becomes the cause of the development of inflammation. Ureaplasma infection in women most often affects the vagina, uterus, fallopian tubes, and ovaries. Besides genital tract infections and infertility, Ureaplasma infection is also associated with adverse pregnancy outcomes and diseases in the newborn. ${ }^{(25)}$

In our study, Ureaplasma spp. was found in $45.2 \%$ of HIV-infected women; co-infection of HPV and Ureaplasma spp. was observed in $35.5 \%$ of cases. This is consistent with the results of other studies. In a study in Ghana, $36.5 \%$ of HIVinfected women were infected by Ureaplasma urealyticum, and $30.21 \%$ were co-infected with HPV. ${ }^{(35)}$ In other studies conducted among HIV-positive women, Ureaplasma urealyticum was detected in $16.3 \%$ persons from West Africa, ${ }^{(36)} 29.4 \%$ from Israel, ${ }^{(37)} 41 \%$ from Italy, ${ }^{(38)}$ and $51.4 \%$ from Tanzania. ${ }^{(39)}$ However, among HIV-positive women from Brazil, Ureaplasma urealyticum was identified in only $2.1 \%$ of cases. ${ }^{(40)}$ Thus, all HIV-infected pregnant women should be screened to decrease the transmission of these pathogens and to protect their own health. ${ }^{(41)}$

HPV infection is one of the most widespread STIs. ${ }^{(42)}$ On average, the frequency of HPV in the world is $10 \%$. The highest frequency level of HPV is observed in Africa - $22.1 \%$, and Central America and Mexico - 20.4\%. In North America, Europe, and Asia the frequency of HPV is $11.3 \%, 8.1 \%$, and $8.0 \%$, respectively. ${ }^{(43)}$ Infection with HPV among HIVpositive women is 2 times higher than in women without HIV infection. ${ }^{(44)}$ In our study, HPV infection was detected in $71 \%$ of HIV-positive women. Our data is comparable with other authors from Russia. So, in St. Petersburg, HPV was detected in $80.5 \%$ of HIV-infected women. ${ }^{(4)}$ Other authors confirm data on the higher frequency of HPV infection in groups of HIV-infected women. Thus, in a study by Shipulina et al., ${ }^{(46)}$ HPV was detected in $38.7 \%$ of HIV-infected women and in only $14.8 \%$ of women without HIV. In a study performed by Marochko et al., ${ }^{(47)} \mathrm{HPV}$ was detected in $58.2 \%$ of HIVinfected women, and in $23 \%$ of women without HIV. Thus, the results obtained in these studies showed that the prevalence of HPV infection in the group of HIV-infected women was 2.5 times higher than in the groups of women without HIV. At the same time, HPV infection in HIV-infected women has increased pathogenicity and significantly increases the risk of cervical lesions and cancer. ${ }^{(48)}$ Therefore, all HIV-infected women should be screened for cervical cancer beginning within 1 year of HIV diagnosis and continue throughout life. ${ }^{(31)}$ 
In conclusion, it should be noted that the prevention of STIs is an important part of the care of an HIV-infected person. ${ }^{(31)}$ As the overall health of persons living with HIV has improved in the last two decades, sexual health, including prevention and detection of STIs, has become an important component of HIV primary care. ${ }^{(49)}$ Most women with HIV are of reproductive age. ${ }^{(50)}$ Previously, it was believed that HIV-infected women should avoid pregnancy and be given the highest priority for family planning services. ${ }^{(51)}$ However, modern antiretroviral drugs against HIV infections, by suppressing the amount of virus in the body, can provide a fulfilling life. Strategies for reducing STI risk include vaccination, mutual monogamy, reducing the number of sexual partners, and abstinence. Comprehensive sex education may also be useful. In this way, the prevention and detection of STIs in HIV-infected individuals remain a public health priority and an integral component of HIV primary care.

\section{Conclusion}

The principal findings of this study are that HIV-infected women of reproductive age have a high frequency of detection of such opportunistic STIs as high-risk HPV and Ureaplasma spp., which are detected in $71 \%$ and $45.2 \%$ of women, respectively. Co-infection of HPV and Ureaplasma spp. is observed in 35.5\% of HIV-positive women. Since HPV and Ureaplasma spp. are highly pathogenic, our results reiterate the need for routine screening in HIV-infected patients for these infections.

This work was performed with the use of equipment of the collective research center "Centre for the development of progressive personalized health technologies" SC FHHRP, Irkutsk

\section{Acknowledgments}

This article contains material that has been discussed at the VIII International Research and Practical Conference «FUNDAMENTAL AND APPLIED ASPECTS OF REPRODUCTION» (December 2021, Irkutsk, Russia). The author thanks all researchers who participated in the oral discussion.

\section{Competing Interests}

The authors declare that they have no competing interests.

\section{References}

1. Manfrin-Ledet L, Porche DJ. The state of science: violence and HIV infection in women. J Assoc Nurses AIDS Care. 2003 Nov-Dec;14(6):56-68. doi: 10.1177/1055329003252056.

2. Leshchenko OYa, Genich EV, Darenskaya MA, Kolesnikova LI. [HIV and infertility: neuro-endocrine and metabolic aspects]. HIV Infection and Immunosuppressive Disorders. 2020;12(4):73-80. doi: 10.22328/2077-9828-2020-
12-4-73-80. [Article in Russian].

3. UNAIDS. Global HIV \& AIDS statistics - Fact sheet. Available from: https://www.unaids.org/en/resources/factsheet.

4. Amirkhanian YA, Kelly JA, Tarima SS, Kuznetsova AV, DiFranceisco WJ, Musatov VB, Yakovlev AA, McAuliffe TL. Prevalence of Alcohol Use and Factors Associated With Problem Drinking in Social Networks of People Living With HIV Infection in St. Petersburg, Russia. AIDS Educ Prev. 2019 Aug;31(4):380-393. doi: 10.1521/aeap.2019.31.4.380.

5. Irkutsk Reginal Centre on AIDS Prevention and Control infectional diseases. Available from: https://aids38.ru/?page_ $\mathrm{id}=35$

6. Ghosn J, Taiwo B, Seedat S, Autran B, Katlama C. HIV. Lancet. 2018 Aug 25;392(10148):685-697. doi: 10.1016/ S0140-6736(18)31311-4.

7. Lewis FMT, Bernstein KT, Aral SO. Vaginal Microbiome and Its Relationship to Behavior, Sexual Health, and Sexually Transmitted Diseases. Obstet Gynecol. 2017 Apr;129(4):643654. doi: 10.1097/AOG.0000000000001932.

8. López de Munain J. [Epidemiology and current control of sexually transmitted infections. The role of STI clinics]. Enferm Infecc Microbiol Clin (Engl Ed). 2019 Jan;37(1):4549. doi: 10.1016/j.eimc.2018.10.015. [Article in English, Spanish].

9. Kolesnikova LI, Kolesnikov SI, Darenskaya MA, Grebenkina LA, Timofeeva EV, Leshchenko OY, Vanteeva OA, Rashidova MA. Otsenka pro- i antioksidantnogo statusa u zhenshchin s VICh i koinfektsiei [Evaluation of the pro- and antioxidant status of women with HIV or coinfection]. Ter Arkh. 2016;88(11):17-21. doi: 10.17116/ terarkh2016881117-21. [Article in Russian].

10. Kolesnikova LI, Darenskaya MA, Kolesnikov SI, Grebenkina LA, Rashidova MA, Timofeeva EV, Leshenko OY, Nikitina OA. Evaluation of lipid peroxidation processes in patients with chronic parenteral viral hepatitis and HIV co-infection depending on degree of inflammatory process activity in the liver. Ter Arkh. 2018 Nov 22;90(11):37-43. doi: 10.26442/terarkh2018901137-43.

11. Siracusano S, Silvestri T, Casotto D. Sexually transmitted diseases: epidemiological and clinical aspects in adults. Urologia. 2014 Oct-Dec;81(4):200-8. doi: 10.5301/ uro.5000101.

12. Leshchenko OYa, Malanova AB. [The ethnic characteristics of the combination of sexually transmitted infections in women with infertility and genital tuberculosis]. HIV Infection and Immunosuppressive Disorders. 2019;11(3):30-36. doi: 10.22328/2077-9828-2019-11-3-3036. [Article in Russian].

13. Leschenko OY, Genich EV. [The reproductive health and sexual behavior of HIV-infected women: the review]. Probl Sotsialnoi Gig Zdravookhranenniiai Istor Med. 2020 Mar;28(2):294-302. doi: 10.32687/0869-866X-2020-28-2294-302. [Article in Russian].

14. Green H, Taleghani S, Nyemba D, Myer L, Davey DJ. Partner notification and treatment for sexually transmitted infections among pregnant women in Cape Town, South Africa. Int J STD AIDS. 2020 Nov;31(13):1282-1290. doi: $10.1177 / 0956462420949789$.

15. Williams CL, Harrison LL, Llata E, Smith RA, Meites E. Sexually Transmitted Diseases Among Pregnant Women: 5 States, United States, 2009-2011. Matern Child Health J. 2018 Apr;22(4):538-545. doi: 10.1007/s10995-017-2422-9. 
16. Rawre J, Agrawal S, Dhawan B. Sexually transmitted infections: Need for extragenital screening. Indian J Med Microbiol. 2018 Jan-Mar;36(1):1-7. doi: 10.4103/ijmm. IJMM_18_46.

17. Belyaeva E, Genich E, Leshchenko O. The Genotype Distribution of Human Papillomavirus among HIV- Infected Women Planning Pregnancy in Irkutsk, Russia. International Journal of Biomedicine. 2021;11(3):346-350. doi:10.21103/ Article11(3) OA11.

18. Podlekareva D, Mocroft A, Dragsted UB, Ledergerber B, Beniowski M, Lazzarin A, Weber J, Clumeck N, Vetter N, Phillips A, Lundgren JD; EuroSIDA study group. Factors associated with the development of opportunistic infections in HIV-1-infected adults with high CD4+ cell counts: a EuroSIDA study. J Infect Dis. 2006 Sep 1;194(5):633-41. doi: $10.1086 / 506366$.

19. Gona P, Van Dyke RB, Williams PL, et al. Incidence of opportunistic and other infections in HIV-infected children in the HAART era. JAMA. 2006;296(3):292-300. doi:10.1001/ jama.296.3.292

20. Iroezindu MO. Disparities in the Magnitude of Human Immunodeficiency Virus-related Opportunistic Infections Between High and Low/Middle-income Countries: Is Highly Active Antiretroviral Therapy Changing the Trend? Ann Med Health Sci Res. 2016;6(1):4-18. doi:10.4103/21419248.180234

21. Dereje N, Moges K, Nigatu Y, Holland R. Prevalence And Predictors Of Opportunistic Infections Among HIV Positive Adults On Antiretroviral Therapy (On-ART) Versus Pre-ART In Addis Ababa, Ethiopia: A Comparative Cross-Sectional Study. HIV AIDS (Auckl). 2019 Oct 4;11:229-237. doi: 10.2147/HIV.S218213.

22. GBD 2015 Disease and Injury Incidence and Prevalence Collaborators. Global, regional, and national incidence, prevalence, and years lived with disability for 310 diseases and injuries, 1990-2015: a systematic analysis for the Global Burden of Disease Study 2015 [published correction appears in Lancet. 2017 Jan 7;389(10064):e1]. Lancet. 2016;388(10053):1545-1602. doi:10.1016/S01406736(16)31678-6

23. GBD 2015 Mortality and Causes of Death Collaborators. Global, regional, and national life expectancy, all-cause mortality, and cause-specific mortality for 249 causes of death, 1980-2015: a systematic analysis for the Global Burden of Disease Study 2015. Lancet. 2016 Oct 8;388(10053):14591544. doi: 10.1016/S0140-6736(16)31012-1. Erratum in: Lancet. 2017 Jan 7;389(10064):e1.

24. Pelvic Inflammatory Disease. The Lecturio Medical Concept Library. Available from: https://www.lecturio.com/ concepts/pelvic-inflammatory-disease/

25. Adamyan LV, Artymuk NV, Belokrinitskaya TE, Zakharova UA, Ksenofontova OL, Kulikov AV, et al. [Cervical incompetence]. Problemy Reproduktsii. 2018; 24(6):578-602. [Article in Russian].

26. Kungurtseva EA, Kolesnikova LI, Darenskaya MA, Ivanova EI, Tunik TV, Nemchenko UM, et al. [Pathogenic potential of the microbiota of various biotopes of women with reproductive disorders and chronic endometritis]. Journal Infectology. 2018;10.S2-1:67-67. [Article in Russian].

27. Kalichman SC, Pellowski J, Turner C. Prevalence of sexually transmitted co-infections in people living with HIV/AIDS: systematic review with implications for using HIV treatments for prevention. Sex Transm Infect. 2011
Apr;87(3):183-90. doi: 10.1136/sti.2010.047514.

28. Msuya SE, Uriyo J, Hussain A, Mbizvo EM, Jeansson S, Sam NE, Stray-Pedersen B. Prevalence of sexually transmitted infections among pregnant women with known HIV status in northern Tanzania. Reprod Health. 2009 Feb 25;6:4. doi: 10.1186/1742-4755-6-4.

29. Frej-Mądrzak M, Gryboś A, Gryboś M, Teryks-Wołyniec D, Jama-Kmiecik A, Sarowska J, Choroszy-Król I. PCR diagnostics of Chlamydia trachomatis in asymptomatic infection by women. Ginekol Pol. 2018;89(3):115-119. doi: 10.5603/GP.a2018.0020.

30. Kalichman SC, Pellowski J, Turner C. Prevalence of sexually transmitted co-infections in people living with HIV/ AIDS: systematic review with implications for using HIV treatments for prevention. Sex Transm Infect. 2011;87(3):183190. doi:10.1136/sti.2010.047514

31. Quilter L, Dhanireddy S, Marrazzo J. Prevention of Sexually Transmitted Diseases in HIV-Infected Individuals. Curr HIV/AIDS Rep. 2017;14(2):41-46. doi:10.1007/s11904017-0350-3

32. Meites E, Llata E, Braxton J, et al. Trichomonas vaginalis in selected U.S. sexually transmitted disease clinics: testing, screening, and prevalence. Sex Transm Dis. 2013;40(11):865869. doi:10.1097/OLQ.0000000000000038

33. Sutton MY, Sternberg M, Nsuami M, Behets F, Nelson AM, St Louis ME. Trichomoniasis in pregnant human immunodeficiency virus-infected and human immunodeficiency virus-uninfected congolese women: prevalence, risk factors, and association with low birth weight. Am J Obstet Gynecol. 1999;181(3):656-662. doi:10.1016/ s0002-9378(99)70509-0

34. Kokkayil P, Dhawan B. Ureaplasma: current perspectives. Indian J Med Microbiol. 2015;33(2):205-214. doi:10.4103/0255-0857.154850

35. Taylor J, Sampene Ossei PP, Pradhan K, Adjah J, Agyeman-Duah E, Afranie BO, Donkor S, Ayibor W. Detecting Ureaplasma urealyticum among HIV-infected women with or without human papillomavirus using real-time PCR with the ANYPLEXTM II STI-7 assay system. J Taibah Univ Med Sci. 2019 May 8;14(3):295-299. doi: 10.1016/j. jtumed.2019.04.001.

36. Djigma F, Ouedraogo C, Sagna T, Ouermi D, Sanogo K, Bisseye C, Kabre A, Pietra V, Simpore J, Nikiema JB, Musumeci S. HIV-infected women of Burkina Faso: a "reservoir" of mycoplasma infection. J Infect Dev Ctries. 2011 Mar 21;5(3):176-81. doi: 10.3855/jidc.950.

37. Banani S, Schlaeffer F, Leibenson L, Saidel-Odes L, Shemer Y, Sagi O, Borer A, Riesenberg K. [Prevalence of sexually transmitted diseases (STD) in HIV positive women in southern Israel]. Harefuah. 2013 Apr;152(4):204-6, 248. [Article in Hebrew].

38. Lanzafame M, Delama A, Lattuada E, Faggian F, Padovani GC, Concia E, Vento S. Prevalence and clinical significance of Ureaplasma urealyticum and Mycoplasma hominis in the lower genital tract of HIV-1-infected women. Infez Med. 2006 Dec;14(4):213-5.

39. Klein C, Samwel K, Kahesa C, Mwaiselage J, West JT, Wood C, Angeletti PC. Mycoplasma Co-Infection Is Associated with Cervical Cancer Risk. Cancers (Basel). 2020 Apr 28;12(5):1093. doi: 10.3390/cancers12051093.

40. Travassos AG, Brites C, Netto EM, Fernandes Sde A, Rutherford GW, Queiroz CM. Prevalence of sexually transmitted infections among HIV-infected women in Brazil. 
Braz J Infect Dis. 2012;16(6):581-585. doi:10.1016/j. bjid.2012.08.016

41. Domingues D, Nogueira F, Tavira L, Exposto F. Micoplasmas: que papel nas infecções humanas? [Mycoplasmas: what is the role in human infections?]. Acta Med Port. 2005 Sep-Oct;18(5):377-83. [Article in Portuguese].

42. Burd EM. Human papillomavirus and cervical cancer. Clin Microbiol Rev. 2003;16(1):1-17. doi:10.1128/CMR.16.1.117.2003

43. Bosch FX, de Sanjosé S. The epidemiology of human papillomavirus infection and cervical cancer. Dis Markers. 2007;23(4):213-227. doi:10.1155/2007/914823

44. Evidence of synergistic relationships between HIV and Human Papillomavirus (HPV): systematic reviews and metaanalyses of longitudinal studies of HPV acquisition and clearance by HIV status, and of HIV acquisition by HPV status. J Int AIDS Soc. 2018;21(6):e25110. doi:10.1002/ jia2.25110

45. Martirosyan MM, Niauru DA, Stepanova YeV, Samarina AV. [Specificities of papilloma virus infection of cervix uteri in HIV-infected women in Saint-Petersburg]. HIV Infection and Immunosuppressive Disorders. 2012; 4(1): 51-56. [Article in Russian].

46. Shipulina OYu, Popova AA, Kravchenko AV, Deulina
MO, Dmitryukova MYu, Romanyuk TN. [Prevalence of high oncogenic risk genotypes of human papillomavirus in HIV-positive and HIV-negative females]. Infectious Disease. 2016;14(4):26-30. doi: 10.20953/1729-9225-2016-4-26-30. [Article in Russian].

47. Marochko KV, Artymuk NV. [Features of papillomavirus infection in human immunodeficiency virus-infected women]. Fundamental and Clinical Medicine. 2017; 2(3): 35-41. [Article in Russian].

48. Rocha-Brischiliari SC, Gimenes F, de Abreu AL, et al. Risk factors for cervical HPV infection and genotypes distribution in HIV-infected South Brazilian women. Infect Agent Cancer. 2014;9(1):6. Published 2014 Feb 11. doi:10.1186/1750-93789-6.

49. Blair JM, McNaghten AD, Frazier EL, Skarbinski J, Huang $\mathrm{P}$, Heffelfinger JD. Clinical and behavioral characteristics of adults receiving medical care for HIV infection --- Medical Monitoring Project, United States, 2007. MMWR Surveill Summ. 2011 Sep 2;60(11):1-20.

50. Cohn SE, Clark RA. Sexually transmitted diseases, HIV, and AIDS in women. Med Clin North Am. 2003;87(5):971995. doi:10.1016/s0025-7125(03)00062-2.

51. Arias E, El-tonsy H, Hafez ES. Conception control and HIV/STD infections. Adv Contracept Deliv Syst. 1988;4(23):97-193. 